\title{
Protective effect of chicken egg yolk immunoglobulins (lgY) against enterotoxigenic Escherichia coli K88 adhesion in weaned piglets
}

Zhaobin Wang ${ }^{1,2 \dagger}$, Jia Li $\mathrm{Li}^{1,2 \dagger}$, Jianzhong $\mathrm{Li}^{1^{*}}$, Yali Li ${ }^{1 *}$, Lixia Wang ${ }^{1}$, Qingping Wang ${ }^{3}$, Lin Fang ${ }^{3}$, Xueqin Ding ${ }^{1}$, Pengfei Huang ${ }^{1}$, Jia Yin ${ }^{1}$, Yulong Yin ${ }^{1,2}$ and Huansheng Yang ${ }^{1,2^{*}}$ (D)

\begin{abstract}
Background: Enterotoxigenic Escherichia coli K88 (E. coli K88) are considered as a major cause of diarrhea and death in newly weaned piglets. Oral passive immunization with chicken egg yolk immunoglobulins (IgY) have attracted considerable attention for treatment of gastrointestinal infection due to its high specificity. In this study it was estimated the protective effect of anti-K88 fimbriae IgY against E. coli K88 adhesion to piglet intestinal mucus in vitro and to investigate the potential use of IgY for controlling E. coli-induced diarrhea in weaned piglets in vivo.

Results: E. coli K88 was incubated with IgY for $24 \mathrm{~h}$, and the bacterial growth profiles showed that specific IgY with a concentration higher than $5 \mathrm{mg} / \mathrm{mL}$ was observed to significantly inhibit the growth of $E$. coli K88 compared to nonspecific yolk powder in a liquid medium. Moreover, pretreatment with $50 \mathrm{mg} / \mathrm{mL}$ of $\lg Y$ was found to significantly decrease the adhesion ability of E. coli K88 to porcine jejunal and ileal mucus, further supported by the observations from our immunofluorescence microscopic analysis. In vivo, administration of IgY successfully protected piglets from diarrhea caused by E. coli K88 challenge. Additionally, IgY treatment efficiently alleviated $E$. coli-induced intestinal inflammation in piglets as the gene expression levels of inflammatory cytokines TNF-a, IL-22, $I L-6$ and $I L-1 \beta$ in IgY-treated piglets remained unchanged after $E$. coli K88 infection. Furthermore, IgY significantly prevented E. coli K88 adhering to the jejunal and ileal mucosa of piglets with E. coli infection and significantly decreased $E$. coli and enterotoxin expression in colonic contents.

Conclusion: Outcome of the study demonstrated that lgY against the fimbrial antigen K88 was able to significantly inhibit the growth of E. coli K88, block the binding of E. coli to small intestinal mucus, and protect piglets from $E$. coli-induced diarrhea. These results indicate that passive immunization with IgY may be useful to prevent bacterial colonization and to control enteric diseases due to $E$. coli infection. The study has great clinical implication to provide alternative therapy to antibiotics in $E$ coli induced diarrhea.
\end{abstract}

Keywords: Egg yolk immunoglobulins (IgY), Escherichia coli K88, Bacteria adhesion, Diarrhea, Piglets

\footnotetext{
* Correspondence: ljzhong@hunnu.edu.cn; liyali06@163.com;

yhs@hunnu.edu.cn

†Zhaobin Wang and Jia Li contributed equally to this work.

${ }^{1}$ Hunan International Joint Laboratory of Animal Intestinal Ecology and

Health, Laboratory of Animal Nutrition and Human Health, College of Life

Sciences, Hunan Normal University, Changsha 410081, Hunan, China

Full list of author information is available at the end of the article
}

(c) The Author(s). 2019 Open Access This article is distributed under the terms of the Creative Commons Attribution 4.0 International License (http://creativecommons.org/licenses/by/4.0/), which permits unrestricted use, distribution, and reproduction in any medium, provided you give appropriate credit to the original author(s) and the source, provide a link to the Creative Commons license, and indicate if changes were made. The Creative Commons Public Domain Dedication waiver (http://creativecommons.org/publicdomain/zero/1.0/) applies to the data made available in this article, unless otherwise stated. 


\section{Background}

Enterotoxigenic Escherichia coli (ETEC) are bacteria that colonized the small intestine and cause severe diarrhea disease in neonatal and weaned piglets. The pathogenesis of E.coli is mainly related to the adhesion of bacteria to the mucus of small intestine using surface proteins known as fimbriae [1]. In addition, ETEC strains can release cytotoxic enterotoxins, including heat-labile (LT) or two heat-stable entertoxins (STa, STb) into intestinal lumen, inducing diarrheal response [2]. It has been reported that K88+ ETEC are responsible for more than half of the piglet mortality each year worldwide [3, 4], leading to significant economic losses [5]. The treatment of $E$. coli infection with antibiotics is widely used in livestock and poultry industries [6]. However, serious concerns have arisen with regard to the potential risks for human health including drug residues in meat products as well as increased antibiotic resistance [7, 8]. Thus, there is an urgent and growing need for the development of novel antimicrobials to prevent ETEC infection and post-weaning diarrhea in piglets.

A wide range of products, including probiotics, herbal extracts and antibodies, have been evaluated as potential alternatives to antibiotics. Among these, oral passive immunization with chicken egg yolk immunoglobulins (IgY) have attracted considerable attention for localized treatment of gastrointestinal infection due to its high specificity. IgY is the major circulating antibody found in chickens and specific IgY production can be achieved by immunizing laying hens with foreign pathogens, which induce immune response leading to high level of IgY antibodies concentrated in the egg yolk. IgY plays a similar biological role as mammalian immunoglobulin $G$ (IgG) [9]. However, IgY possesses many advantages over traditional antibodies from mammalians, such as costeffectiveness, non-invasive, stable nature, high efficiency as well as good safety [10]. Moreover, it has been reported that IgY is fairly resistant to digestion by intestinal proteases [3].

Oral administration of specific IgY has been reported to be highly effective against a wide variety of intestinal pathogenic microorganisms which cause diarrhea in animals, such as Salmonella spp., Eimeria spp., bovine rotaviruses, as well as porcine epidemic diarrhea virus [5]. Several mechanisms by which IgY counteracts pathogen activity have been proposed, including inhibition of bacterial adhesion, agglutination of bacteria, as well as toxin neutralization, while inhibition of adhesion is considered the primary mechanism through which IgY functions [7]. Thus, supplementing piglets with specific IgY against E. coli fimbrial antigens to inhibit the attachment of bacteria to intestine offers a potential solution to prevent ETEC-induced diarrhea in piglets $[11,12]$. The objective of this study was to investigate both in vitro and in vivo inhibitory effects of E. coli K88-specific IgY on the adhesion ability of $E$. coli to intestinal mucus, and its efficiency to prevent piglets from $E$. coli-induced diarrhea.

\section{Results}

Growth inhibitory effect of specific IgY on $E$. coli K88

To investigate the growth inhibitory effect of IgY, E. coli K88 was incubated with yolk powder or E. coli-specific IgY ranging from 0 to $50 \mathrm{mg} / \mathrm{mL}$ in LB liquid medium for $24 \mathrm{~h}$ and the bacterial growth profiles were recorded. As shown in Fig. 1, a potent inhibitory effect of anti-E. coli IgY on the bacterial growth was observed in a dose-dependent manner during incubation. Remarkably, specific IgY with a concentration higher $(P<0.001)$ than $5 \mathrm{mg} / \mathrm{mL}$ was found to significantly inhibit the growth of $E$. coli $\mathrm{K} 88$ in comparison to nonspecific yolk powder (Fig. $1 \mathrm{c}$ to $\mathrm{f}$ ).

\section{Inhibition of $E$. coli $\mathbf{K} 88$ adhesion by specific $\lg Y$}

To examine the adhesion inhibitory effect of IgY, E. coli K88 was pretreated with specific IgY and the number of bacteria adhered to crude porcine jejunal or ileal mucus was determined by bacterial colony counts. Results showed that pretreatment with $50 \mathrm{mg} / \mathrm{mL}$ of IgY significantly decreased the adhesion ability of E. coli K88 to jejunal mucus (Fig. 2a). In the next set of experiment, the adhesion of FITC-labelled E. coli to intestinal mucus was studied and adherence ratio was calculated by measuring the fluorescence intensity. Data showed that pretreatment with IgY markedly reduced the adherence index of $E$. coli to both jejunal $(P<0.001)$ and ileal $(P<0.001)$ mucus compared with nonspecific yolk powder (Fig. 2c and d). This observation is further supported by the results from our immunofluorescence microscopic analysis revealing decreased bacterial adhesion to mucus in specific IgY pretreatment group (Fig. 2e to g). Collectively these findings demonstrate that IgY is more effective to reduce the adhesion ability of $E$. coli K88 than yolk powder.

\section{Protective effect of $\lg Y$ against $E$. coli diarrhea in piglets}

To evaluate the in vivo effectiveness of IgY against E. coli infection, 15 piglets in each group diets supplemented with $400 \mathrm{mg} / \mathrm{kg}$ of non-specific yolk powder (Group II, negative control) or $400 \mathrm{mg} / \mathrm{kg}$ of yolk power enriched with ETEC-specific IgY (Group III) were orally inoculated with $5 \mathrm{~mL}$ of $E$. coli $\mathrm{K} 88$ at a dose of $10^{8} \mathrm{CFU} / \mathrm{mL}$ and the frequency and severity of diarrhea were recorded. Results showed that piglets with nonspecific yolk powder treatment developed severe diarrhea $(P=0.034)$ $12 \mathrm{~h}$ after $E$. coli challenge compared to uninfected piglets (Group I). In contrast, there was no significant difference in diarrhea scores between IgY-treated piglets and uninfected piglets post infection (Fig. 3). Interestingly, IgY-treated piglets all recovered (diarrhea score = 0 ) by $72 \mathrm{~h}$ post challenge. These results suggest that IgY 


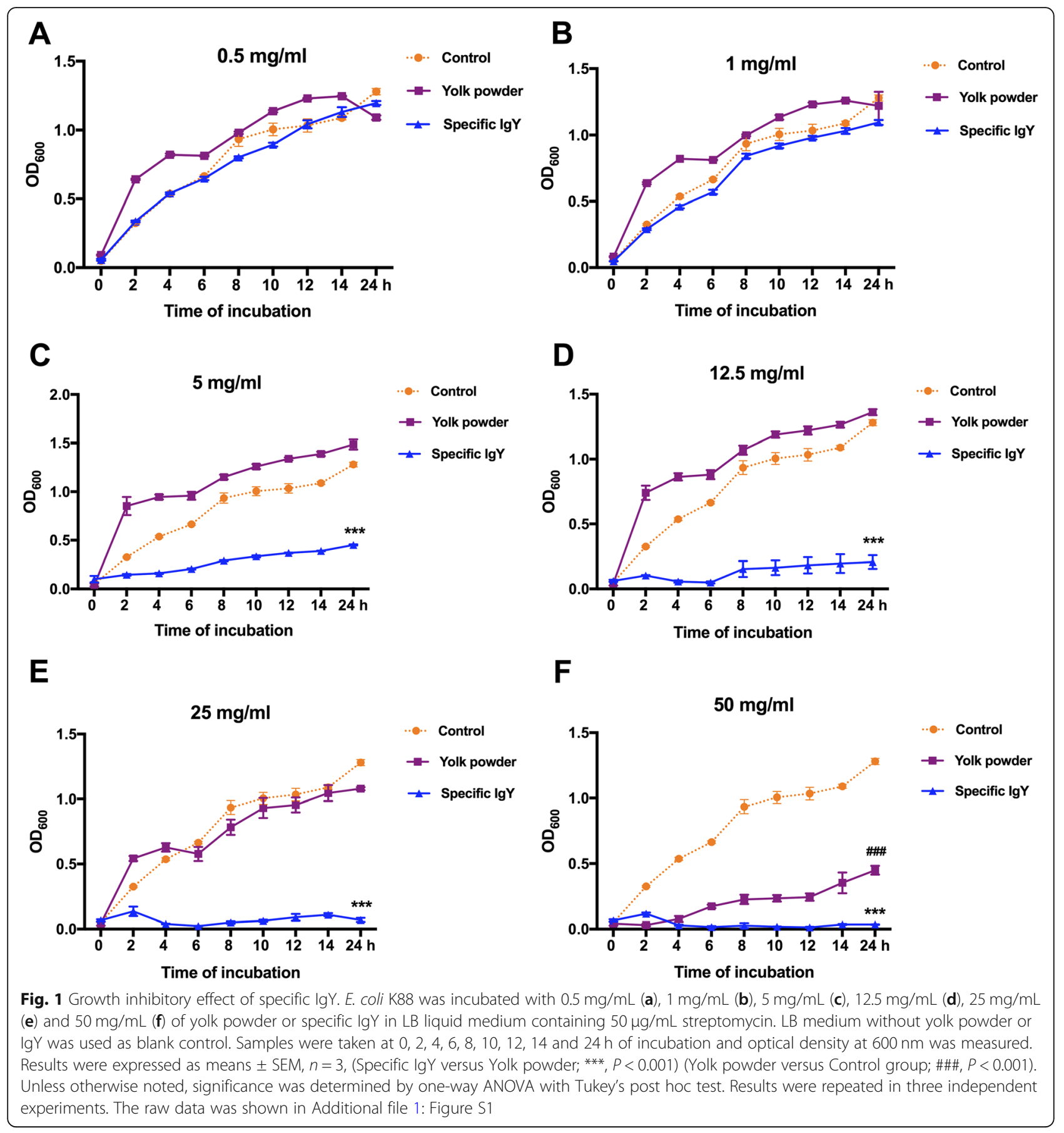

treatment can effectively protect piglets from $E$. coli-induced diarrhea compared to nonspecific yolk powder.

Inflammatory profiles in jejunal and ileal mucosa post infection

To further analyze the inflammatory changes in intestinal mucosa, relative gene expressions of inflammatory cytokines $T N F-\alpha, I L-22, I L-6$ and $I L-1 \beta$ were detected. As illustrated in Fig. 4, oral administration of IgY was able to alleviate intestinal inflammation as the gene expression levels of TNF- $\alpha, I L-22, I L-6$ and $I L-1 \beta$ in IgYtreated piglets remained unchanged after E. coli K88 infection. In contrast, the expression levels of TNF- $\alpha(P=$ $0.039), I L-22(P=0.033)$ and $I L-6(P=0.016)$ in jejunal mucosa at $12 \mathrm{~h}$ and $I L-22(P=0.030)$ expression in ileal mucosa at $72 \mathrm{~h}$ post infection, were markedly upregulated in nonspecific yolk powder group (Fig. 4 a, c, d and e). Noticeably, specific IgY resulted in a remarkable decrease $(P<0.05)$ in $I L-6$ expression in jejunal mucosa at $12 \mathrm{~h}$ post challenge in contrast to yolk powder treatment 

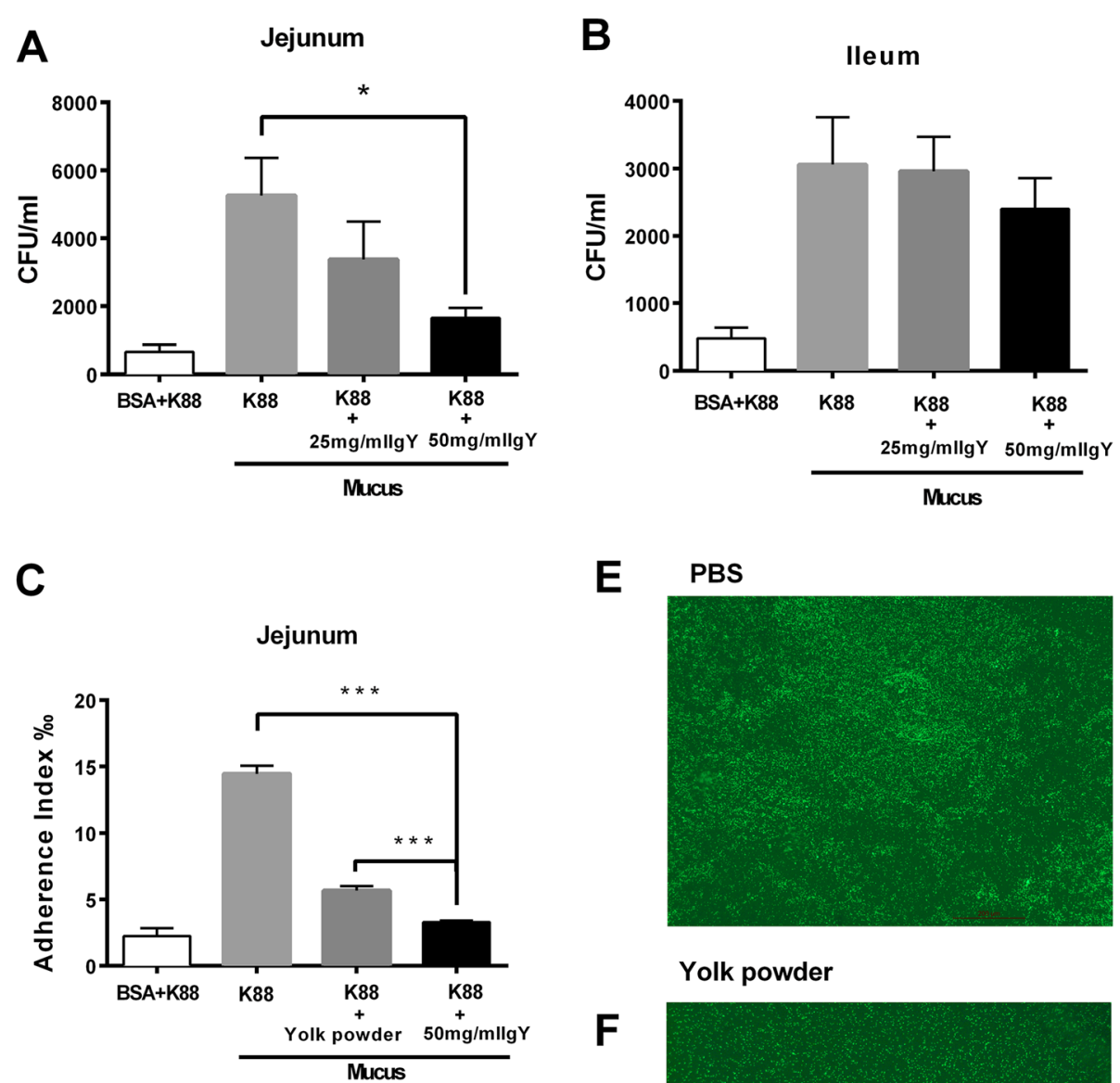

E PBS
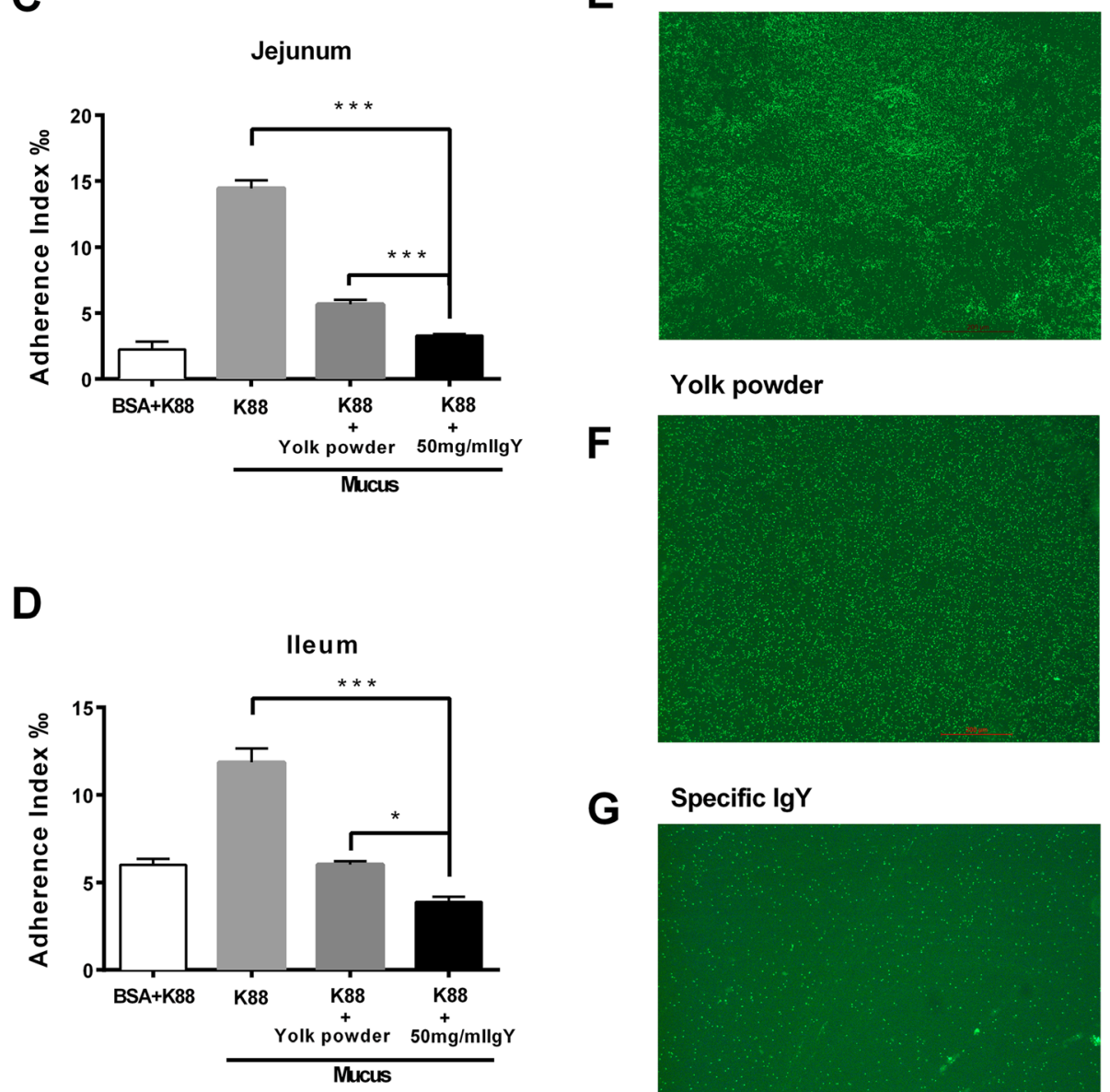

\section{Yolk powder}

F

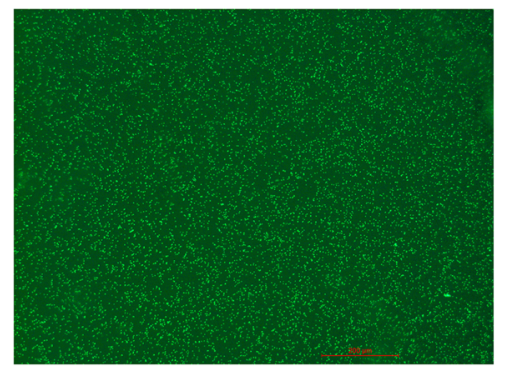

\section{G Specific $\lg Y$}

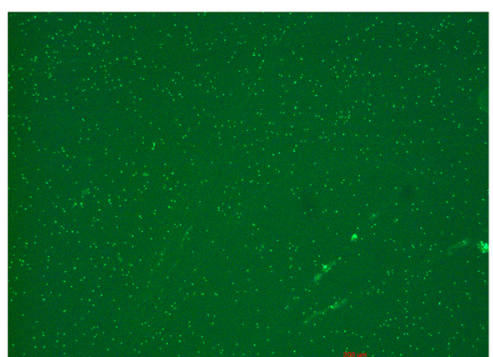

Fig. 2 Inhibition of E. coli K88 adhesion by specific IgY. E. coli K88 was pretreated with specific $\lg Y$ and the number of bacteria adhered to crude porcine jejunal (a) and ileal (b) mucus was determined by bacterial colony counts. FlTC-labelled E. coli was incubated with $50 \mathrm{mg} / \mathrm{mL}$ of yolk powder or specific lgY. Bacterial adherence to jejunal (c) and ileal (d) mucus was measured by fluorescence intensity changes. Results were expressed as means $\pm \mathrm{SEM}, n=3,\left(^{*}, P<0.05\right.$; ***, $\left.P<0.001\right)$. FITC-labelled $E$. coli was pre-treated with PBS $(\mathbf{e}), 50 \mathrm{mg} / \mathrm{mL}$ of yolk powder (f) or specific $\lg Y(\mathbf{g})$. Immunofluorescence microscopy data show the adhesion of $E$. coli K88 (in Green) to jejunal mucus (magnification $\times 10$ ). Data shown are generated from three independent experiments. The raw data was shown in Additional file 2: Figure S2 


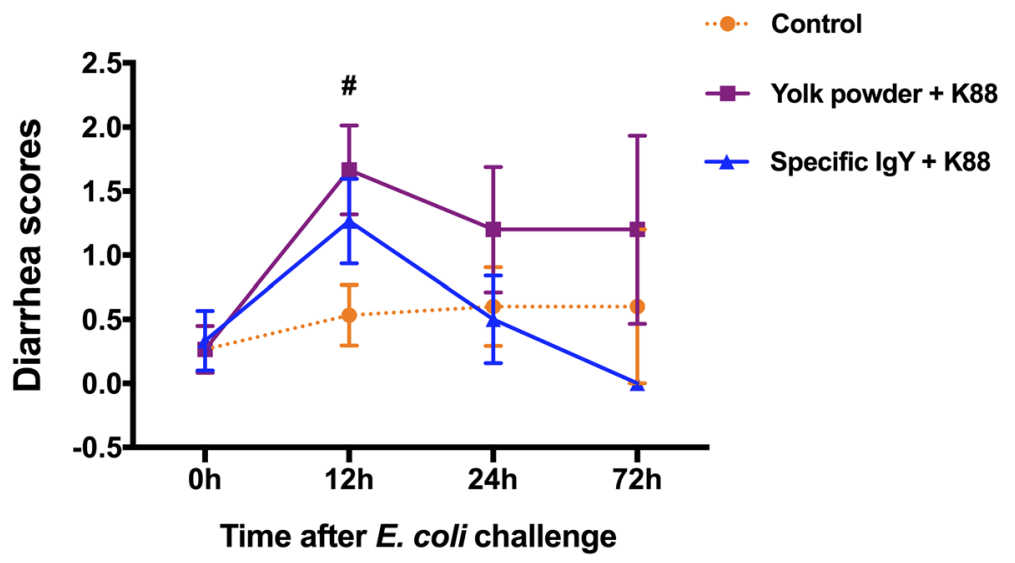

Fig. 3 Diarrhea scores of piglets after $E$. coli challenge. Piglets pretreated with yolk powder or specific lgY were orally inoculated with $5 \mathrm{~mL}$ of $E$. coli K88 at a dose of $10^{8} \mathrm{CFU} / \mathrm{mL}$. Diarrhea scores were recorded: $(0=$ normal; $1=$ soft feces; $2=$ mild diarrhea; $3=$ watery stool). Results were expressed as means \pm SEM ( $n=5-15$ per group). Yolk powder (Group II) versus Control group (Group I); \#, $P<0.05$. The raw data was shown in Additional file 3: Figure S3

(Fig. 4e). Taken together, these data indicate that oral passive immunization with IgY can effectively ameliorate the E. coli-induced intestinal inflammation in piglets.

\section{Counts of $E$. coli K88 adhering to intestinal mucosa and enterotoxin expression in luminal content}

To assess the protective effects of IgY in vivo, numbers of $E$. coli that adhered to the intestinal mucosa were counted by plating serial dilutions of mucosal homogenates onto MacConkey agar plates and genes encoding fimbriae and enterotoxins were quantified by PCR analysis. Results showed that the attachment of E. coli K88 to jejunal and ileal mucosa was inhibited by specific IgY (Group III) while the counts of $E$. coli adhering to the intestinal mucosa were remarkably $(P<0.05)$ elevated in yolk powder group (Group II) at $72 \mathrm{~h}$ post infection in contrast to uninfected control group (Group I) (Fig. 5a and b). Additionally, lower number of $E$. coli were presented in ileal mucosa in IgY group at $12 \mathrm{~h}$ after infection than those in yolk powder group $(P<0.05)$ (Fig. 5b). Moreover, significantly decreased $E$. coli and heat-stable enterotoxin b (STb) expression in colonic contents was observed in IgY group at $72 \mathrm{~h}$ after infection (Fig. 5c and e). Furthermore, a trend of decreased expression of STa was found in ileal contents in IgY group (Fig. 5d). These findings imply that IgY exhibits protective efficacy against bacterial adhesion to the mucosal surface and reduce enterotoxin expression.

\section{Discussion}

ETEC is a major cause of diarrhea disease in newly weaned piglets. Among the different ETEC strains (K88-, K99-, or 987P-expressing strains), those expressing K88 fimbrial antigens are the most prevalent [13]. These fimbriae mediate the attachment of E. coli K88- expressing strains to the intestinal epithelial cells and also to the mucus layer lining the small intestine, and thereafter ETEC elaborates one or two enterotoxins (LT, STa or STb), thereby inducing massive fluid and electrolyte secretion into the gut lumen. Specific egg yolk immunoglobulin (IgY) are prepared from the egg yolk of hens immunized with fimbrial antigens of $E$. coli and used for passive immunization applications in medical fields $[7,14]$. In the present study, we evaluated the protective role of IgY against E. coli K88 by assessing its ability to inhibit the growth and adhesion of E. coli to piglet intestinal mucus and we also investigated the potential of this approach for controlling $E$. coli-induced diarrhea and intestinal inflammation in weaned piglets.

Previous studies have shown that the K88 fimbriae can specifically adhere to their receptors in both intestinal brush borders and mucus preparations of piglets [13]. Results of our in vitro study clearly showed that E. colispecific IgY possessed a potent inhibitory effect on the bacterial growth in a dose-dependent manner with an effective concentration of $5 \mathrm{mg} / \mathrm{mL}$ specific IgY compared to nonspecific yolk powder. In agreement with our findings, Shi et al. reported that specific IgY potently inhibited the growth of pan-drug-resistant Acinetobacter baumannii in a dose-dependent manner at concentrations ranging from $5 \mathrm{mg} / \mathrm{mL}$ to $20 \mathrm{mg} / \mathrm{mL}$, while nonspecific IgY did not show significant growth inhibition to the bacteria [15]. Moreover, in the present study, specific IgY was found to significantly decrease the adhesion ability of E. coli K88 to porcine small intestinal mucus, further supported by the results from our immunofluorescence microscopic analysis. Our current data support earlier reports that blocking the binding of pathogens to target host cells is the dominant mechanism for IgY function [16]. Zhen et al. found that structural alteration 


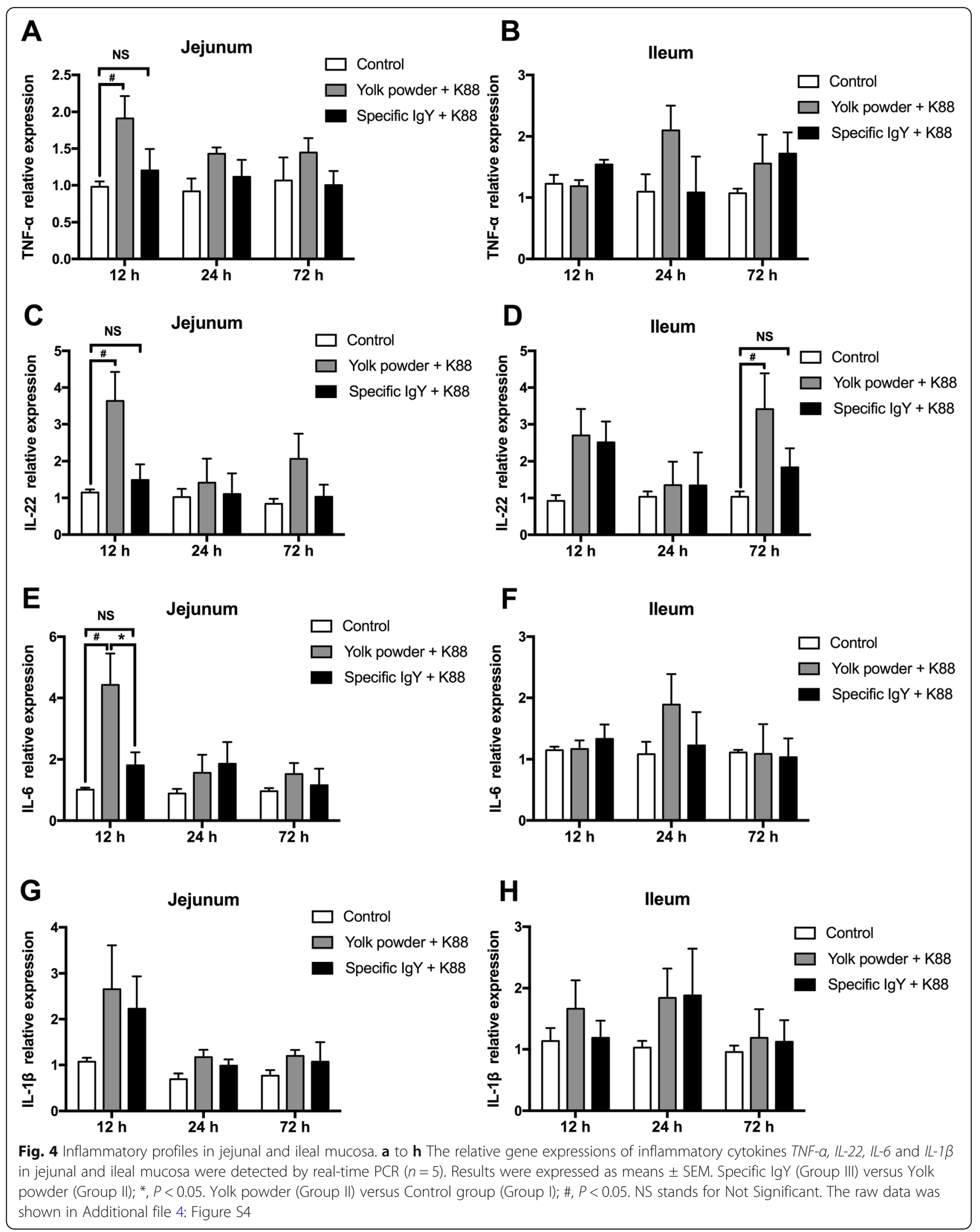




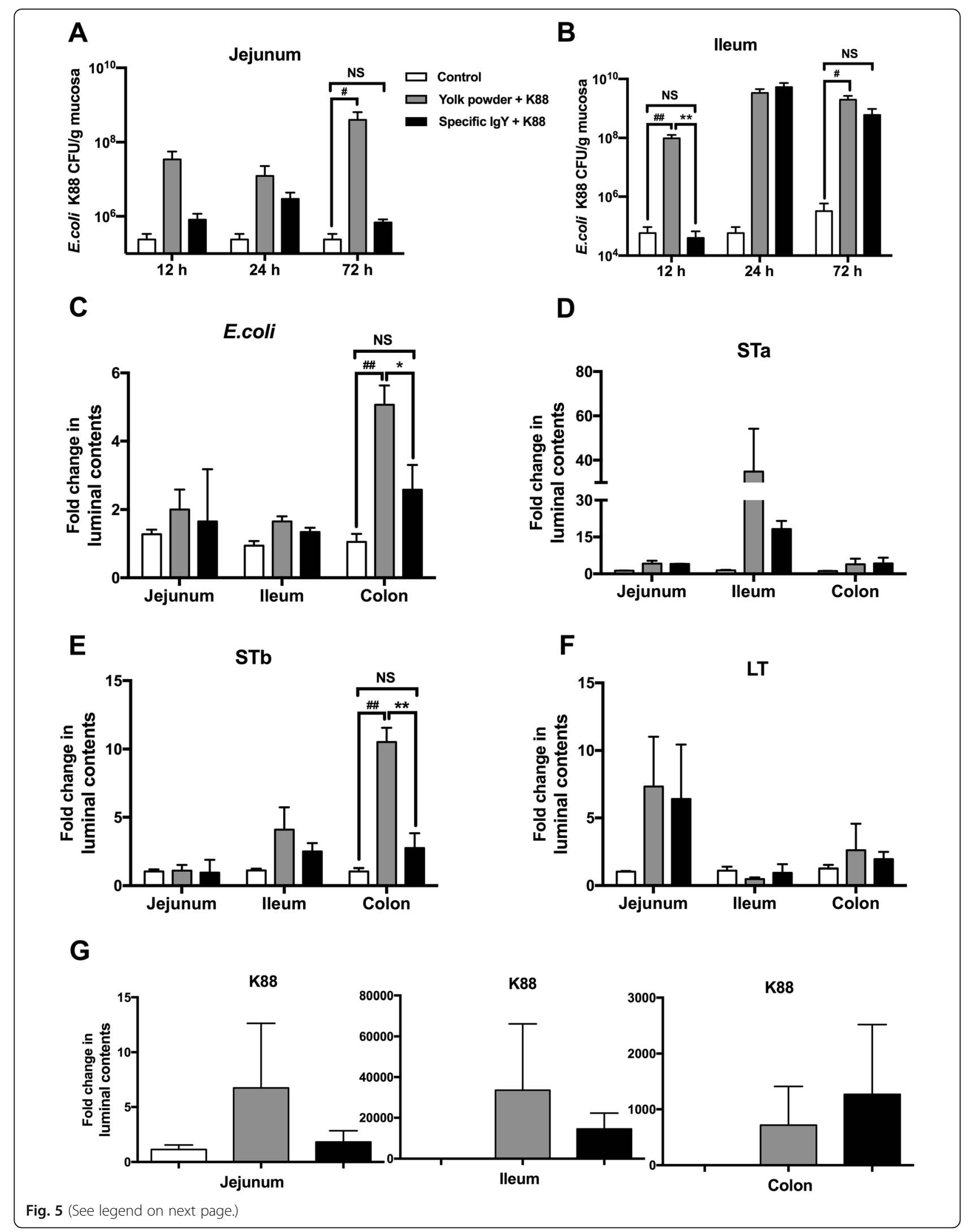


(See figure on previous page.)

Fig. 5 Counts of E. coli K88 adhering to intestinal mucosa and enterotoxin expression in luminal content. Mucosal samples were obtained at 12, 24 and $72 \mathrm{~h}$ post infection and numbers of E. coli that adhered to jejunal (a) and ileal (b) mucosa were counted by plating serial dilutions of mucosal homogenates onto MacConkey agar plates. Intestinal digesta samples were collected at $72 \mathrm{~h}$ after infection and fold changes of genes encoding E. coli (c), STa (d), STb (e), LT (f) and K88 (g) were quantified by PCR analysis $(n=5)$. Results were expressed as means \pm SEM. Specific IgY (Group III) versus Yolk powder (Group II); ${ }^{*}, P<0.05,{ }^{*}, P<0.01$. Yolk powder (Group II) versus Control group (Group I); \#, $P<0.05, \# \#, P<0.01$. NS stands for Not Significant. The raw data was shown in Additional file 5: Figure S5

of $E$. coli cell surface caused by binding with specific IgY and these alterations may impede adhesion of bacteria to target cell surfaces [16]. Lee et al. reported that specific IgY could attach to components exposed on the surface of $S$. typhimurium, leading to structural alterations [14]. Jin et al. reported that antibodies against the fimbriae of $E$. coli K88+ could block the binding of $E$. coli $\mathrm{K} 88+$ to the mucosal receptor. Similarly, Imberechts et al. reported that chicken egg-yolk containing F18ab antibodies inhibited the attachment of F18ab positive $E$. coli bacteria to the intestinal mucosa [17]. Jin et al. also reported that E. coli K88 pre-incubated with egg antibodies against the fimbriae was not able to adhere to intestinal mucus of piglets [18]. Additionally, Lee et al. found that Salmonella-specific IgY could bind to the antigens expressed on the Salmonella surface, leading to structural alterations and functional impairment [14]. Sunwoo et al. also observed structural alterations of the bacterial surface bound by specific E. coli O157:H7 IgY, resulting in bacterial growth inhibition [19]. Consistent with these findings, our results confirm that binding of IgY antibodies to the K88 fimbriae can effectively block fimbriae-mediated attachment of bacteria to their receptors on intestinal epithelial surfaces.

Currently, IgY has been focused as an alternative approach for controlling and preventing diarrhea in animals caused by enteric pathogens [20], due to its ability to inhibit bacterial adhesion and colonization [21], as well as to neutralize various bacterial toxins [22]. To evaluate the in vivo effectiveness of IgY against $E$. coli infection, we examined the protective capacity of IgY against E. coli $\mathrm{K} 88$ induced diarrhea and intestinal inflammation in piglets. The clinical response of $E$. coli K88 challenged piglets revealed that IgY-treated piglets all recovered from E. coli K88 induced-diarrhea and exhibited no clinical signs $72 \mathrm{~h}$ after inoculation. In contrast, piglets have been in diarrhea for $72 \mathrm{~h}$ without IgY protection, and have a diarrhea score $>1.2$. These results were in accordance with the work of $\mathrm{Li}$ et al., who demonstrated that treatment of infected pigs with IgY significantly reduced the K88+ ETEC-induced diarrhea in 40day-old pigs [23]. TNF- $\alpha$ and IL-6 are typical proinflammatory cytokines and have been used as potential markers for ongoing bacterial infections in piglets [24], while IL-22 is essential for maintaining mucosal barrier homeostasis against specific pathogens by eliciting innate defense response [25]. In this study, our real-time PCR analysis clearly demonstrated that E. coli K88 failed to induce inflammatory cytokines $T N F-\alpha, I L-22$ and $I L-6$ upregulation in IgY-treated piglets, suggesting that IgY treatment can effectively alleviate the $E$. coli-induced intestinal inflammation in piglets. Consistent with findings obtained from our in vitro adhesion test, specific IgY effectively prevented $E$. coli K88 adhering to the jejunal and ileal mucosa in vivo while greater number of $E$. coli were presented in nonspecific yolk powder group. Moreover, diarrhea-causing enterotoxins are generally considered to be the main virulence factors associated with $E$. coli and may also play a role in the colonization process $[26,27]$. In the current study, IgY significantly reduce $E$. coli and enterotoxin expression in colonic contents, indicating a protective role of IgY against E. coli in piglets.

\section{Conclusions}

In conclusion, anti-K88 fimbrial IgY utilized in our study, was able to significantly inhibit the growth of $E$. coli K88, block the adhesion of bacteria to intestine mucus, and reduce $E$. coli-induced diarrhea, as verified in both in vitro and in vivo experiments. The study has great clinical implication to provide alternative therapy to antibiotics in $E$ coli induced diarrhea.

\section{Methods \\ Egg Yolk immunoglobulins}

Specific chicken egg yolk immunoglobulins (IgY) with high titers of anti-K88 (50,000), and nonspecific yolk powder were provided by Zyme Fast (Changsha) Biotechnology Co., Ltd. Piglets were fed with egg yolk powder containing IgY, which was not purified. IgY were obtained from egg yolk after immunization of hens with E. coli fimbrial antigens. Nonspecific yolk powders were prepared from the yolks of eggs laid by non-immunized hens, and used as negative control.

\section{Bacteria and culture conditions}

Streptomycin-resistant E. coli K88 strain (W25K) was obtained from the Institute of Subtropical Agriculture, Chinese Academy of Sciences. The bacteria were cultured in Luria-Bertani (LB) broth or on MacConkey agar containing $50 \mu \mathrm{g} / \mathrm{mL}$ streptomycin at $37^{\circ} \mathrm{C}$. 


\section{Growth inhibition assay}

This assay was conducted to investigate whether the anti-E. coli IgY could inhibit $E$. coli growth in a liquid medium. Based on previous studies [16, 18], specific IgY or nonspecific yolk powder were reconstituted to $0.5,1,5,12.5,25$ and $50 \mathrm{mg} / \mathrm{mL}$ with $\mathrm{LB}$ liquid medium containing $50 \mu \mathrm{g} / \mathrm{mL}$ streptomycin. LB medium without IgY or yolk powder was used as blank control. IgY and yolk powder solutions were sterilized by using a $0.22 \mu \mathrm{m}$ membrane filter (Millipore), in which E. coli $\mathrm{K} 88$ were added at a final concentration of $5 \times 10^{6} \mathrm{CFU} / \mathrm{mL}$. Mixtures of bacteria and IgY or yolk powder were incubated at $37^{\circ} \mathrm{C}$ with shaking. $\mathrm{OD}_{600 \mathrm{~nm}}$ of the suspensions was measured by a spectrophotometer (RUNQEE, Shanghai) at $0,2,4,6,8,10,12,14$ and $24 \mathrm{~h}$ of incubation [28]. All experiments were repeated three times in triplicates.

\section{Intestinal mucus isolation}

Porcine small intestinal mucus was isolated as described by $[18,29]$ with modifications. Briefly, crude mucus was gently scraped from jejunum and ileum of healthy piglets and then centrifuged at $1,3000 \times g$ at $4{ }^{\circ} \mathrm{C}$ for $10 \mathrm{~min}$ to remove solids. After filtering, protein concentration was measured using bicinchoninic acid protein assay kit. Mucus was then diluted in $1 \mathrm{mM}$ HEPES-Hanks' buffer to a final concentration of $1 \mathrm{mg} / \mathrm{mL}$ and stored at $80{ }^{\circ} \mathrm{C}$ until use.

\section{Adhesion inhibition assay with $E$. coli $\mathrm{K} 88$}

Intestinal mucus was loaded into 24-well plate (Thermo Fisher Scientific) and immobilized at $4{ }^{\circ} \mathrm{C}$ overnight. Plates coated with bovine serum albumin (BSA) served as a negative control. E. coli K88 was mixed with PBS, $25 \mathrm{mg} / \mathrm{mL}, 50 \mathrm{mg} / \mathrm{mL}$ of specific IgY [diluted in sterile PBS] at a final concentration of $10^{8} \mathrm{CFU} / \mathrm{mL}$, followed by incubation at $37^{\circ} \mathrm{C}$ for $1 \mathrm{~h}$ with shaking. Then mixtures were added to plate coated with mucus in triplicate and incubated at $37^{\circ} \mathrm{C}$ for another $2 \mathrm{~h}$. Adherent bacteria were collected by adding $500 \mu \mathrm{L}$ of $0.1 \%$ Triton $\mathrm{X} 100$, diluted in sterile PBS, and then cultured on MacConkey agar containing $50 \mu \mathrm{g} / \mathrm{mL}$ streptomycin at $37^{\circ} \mathrm{C}$ overnight $(12 \mathrm{~h})$. The Colony-forming units (CFU) were quantified.

\section{Adhesion inhibition assay with FITC-labelled bacteria}

Intestinal mucus was loaded into black 96-well plate and immobilized at $4{ }^{\circ} \mathrm{C}$ overnight. E. coli $\mathrm{K} 88$ was labelled with fluorescein isothiocyanate (FITC, Sigma) in dark for $1 \mathrm{~h}$, and FITC-labelled E. coli $\left(10^{8} \mathrm{CFU} /\right.$ $\mathrm{mL}$ ) was then incubated with $50 \mathrm{mg} / \mathrm{mL}$ of yolk powder or specific $\operatorname{IgY}$ at $37^{\circ} \mathrm{C}$ for $1 \mathrm{~h}$. After incubation, the bacteria and IgY mixtures were added into 96- well plate coated with mucus and the fluorescence intensity at this point was designated as F1. After incubation for $1 \mathrm{~h}$, adherent bacteria were recovered by $0.1 \%$ Triton $\mathrm{X} 100$, and the fluorescence intensity was measured, designated as F2. The adherence index was calculated as the ratio of $\mathrm{F} 2 / \mathrm{F} 1$.

\section{Immunofluorescence microscopy}

FITC-labelled E. coli was pre-treated with $50 \mathrm{mg} / \mathrm{mL}$ of yolk powder or specific IgY, and then smeared on the microscope slides coated with porcine jejunal mucus. After incubation for $1 \mathrm{~h}$, slides were washed with PBS, fixed in $4 \%$ paraformaldehyde, mounted by antifluorescence quencher, and covered with cover slips [30]. All slides were analyzed by immunofluorescence microscopy (Leica DM3000).

\section{Animals, housing, and experimental design}

Animal experiments were conducted under protocols approved by the Institutional Animal Care and Use Committee of Hunan Normal University. Thorough disinfection and sterilization of the pig house environment before the test to ensure that no pathogens infect the piglets. A total of 45 [(Landrace $\times$ Yorkshire $)$ $\times$ Duroc] piglets (initial body weight (BW) $7.44 \pm 0.14$ kg; Hunan Bao Dong Animal Farming Development Co., Ltd) were weaned at 21 days of age. We randomly assigned them into three groups of 15 piglets per group. Group I (uninfected control) and Group II (negative control with infection) were fed basal diet (Table 1) supplemented with $400 \mathrm{mg} / \mathrm{kg}$ nonspecific yolk powder, while Group III were supplemented with $400 \mathrm{mg} / \mathrm{kg}$ specific IgY for 6 consecutive days. Basal diet contained no antibiotics. Throughout the experimental period, feed and water were provided ad libitum. On day 3, all piglets except Group I (uninfected control) were orally challenged with $5 \mathrm{~mL}$ of E.coli K88 $\left(10^{8} \mathrm{CFU} / \mathrm{mL}\right)$ with a syringe [31]. After 12,24 and $72 \mathrm{~h}$ infection, five piglets from each treatment were selected randomly, and sacrificed by intravenous administration of $4 \%$ sodium pentobarbital solution (40 mg/kg BW) to euthanize for sampling. Clinical signs of each pig were monitored throughout the experiment. Diarrhea scores were recorded: (0), normal; (1), soft feces; (2), mild diarrhea; (3), severe diarrhea (watery stool) [32].

\section{Intestinal $E$. coli enumeration}

Intestinal mucosal samples were obtained by gently scraping the surface of jejunal and ileal segments at 12,24 and $72 \mathrm{~h}$ post infection. Mucosal samples were weighed, homogenized, serially diluted, and plated on MacConkey agar plates containing $50 \mu \mathrm{g} /$ 
Table 1 Composition of experimental diets on as fed-basis

\begin{tabular}{ll}
\hline Component & Content, $\%$ \\
\hline Corn & 37.66 \\
Extruded corn & 20.00 \\
Soybean meal, 43\% CP & 8.00 \\
Concentrated soy protein & 7.00 \\
Whey & 10.00 \\
Fish meal, 63\% CP & 5.00 \\
Plasma protein powder & 4.50 \\
L-Lys HCl, 98\% & 0.33 \\
DL-Met & 0.08 \\
L-Thr & 0.03 \\
L-Trp & 0.01 \\
Glucose & 2.00 \\
Soybean oil & 2.00 \\
Limestone & 1.04 \\
Monocalcium phosphate & 0.50 \\
Choline chloride, 50\% & 0.10 \\
Antioxidants & 0.05 \\
Zinc oxide & 0.30 \\
Citric acid & 0.30 \\
premix & 1.00 \\
\hline
\end{tabular}

apremix supplied per kilogram of feed: 10,000 IU of Vitamin A, $1000 \mathrm{IU}$ of Vitamin $D_{3}, 80 \mathrm{IU}$ of Vitamin $\mathrm{E}, 2.0 \mathrm{mg}$ of Vitamin $\mathrm{K}_{3}, 0.03 \mathrm{mg}$ of Vitamin $B_{12}$, $12 \mathrm{mg}$ of riboflavin, $40 \mathrm{mg}$ of niacin, $25 \mathrm{mg}$ of d-pantothenic acid, $0.25 \mathrm{mg}$ of biotin, $1.6 \mathrm{mg}$ of folic acid, $3.0 \mathrm{mg}$ of thiamine, $2.25 \mathrm{mg}$ of pyridoxine, $300 \mathrm{mg}$ of choline chloride, $150 \mathrm{mg}$ of Fe $\left(\mathrm{FeSO}_{4}\right), 100 \mathrm{mg}$ of $\mathrm{Zn}\left(\mathrm{ZnSO}_{4}\right), 30 \mathrm{mg}$ of $\mathrm{Mn}$ $\left(\mathrm{MnSO}_{4}\right), 25 \mathrm{mg}$ of $\mathrm{Cu}\left(\mathrm{CuSO}_{4}\right), 0.5 \mathrm{mg}$ of I $\left(\mathrm{KIO}_{3}\right), 0.3 \mathrm{mg}$ of $\mathrm{Co}\left(\mathrm{CoSO}_{4}\right), 0.3 \mathrm{mg}$ of $\mathrm{Se}\left(\mathrm{Na}_{2} \mathrm{SeO}_{3}\right)$, and $4.0 \mathrm{mg}$ of ethoxyquin

Table 2 Cytokines primers used for the real time PCR

\begin{tabular}{|c|c|c|c|c|}
\hline $\begin{array}{l}\text { Target } \\
\text { gene }\end{array}$ & Orientation & Sequence $\left(5^{\prime}-3^{\prime}\right)$ & $\begin{array}{l}\mathrm{Tm} \\
\left({ }^{\circ} \mathrm{C}\right) \\
\end{array}$ & $\begin{array}{l}\text { Product size } \\
(\mathrm{bp})\end{array}$ \\
\hline \multirow[t]{2}{*}{$\beta$-actin } & Forward & $\begin{array}{l}\text { AGTTGAAG } \\
\text { GTGGTCTCGTGG }\end{array}$ & 57.4 & 216 \\
\hline & Reverse & $\begin{array}{l}\text { TGCG } \\
\text { GGACATCAAGGAGAAG }\end{array}$ & & \\
\hline \multirow[t]{2}{*}{ TNF-a } & Forward & $\begin{array}{l}\text { ACAG } \\
\text { GCCAGCTCCCTCTTAT }\end{array}$ & 53.9 & 102 \\
\hline & Reverse & $\begin{array}{l}\text { CCTC } \\
\text { GCCCTCCTGAATAAAT }\end{array}$ & & \\
\hline \multirow[t]{2}{*}{$1 L-22$} & Forward & $\begin{array}{l}\text { AGCA } \\
\text { AGCGTGAAGGTGCGGTT }\end{array}$ & 60 & 169 \\
\hline & Reverse & $\begin{array}{l}\text { GCGG } \\
\text { ACATCTGGGAGCCCTIT }\end{array}$ & & \\
\hline \multirow[t]{2}{*}{ IL-6 } & Forward & $\begin{array}{l}\text { GGCAAAAG } \\
\text { GGAAAGAATCCAG }\end{array}$ & 57 & 87 \\
\hline & Reverse & $\begin{array}{l}\text { CGTT } \\
\text { CTGTGACTGCAGCTTATCC }\end{array}$ & & \\
\hline \multirow[t]{2}{*}{$I L-1 \beta$} & Forward & CCTGGACCTTGGTTCTCT & 53 & 123 \\
\hline & Reverse & GGATTCTTCATCGGCTTCT & & \\
\hline
\end{tabular}

Abbreviations: TNF- $a$ tumor necrosis factor alpha, IL-22 interleukin $22, I L-6$ interleukin $6, I L-1 \beta$ interleukin $1 \beta, \operatorname{Tm}\left({ }^{\circ} \mathrm{C}\right)$ melting temperature
Table 3 Primers used for amplification of E. coli and enterotoxins in digesta samples

\begin{tabular}{|c|c|c|c|c|}
\hline Target gene & Orientation & Sequence $\left(5^{\prime}-3^{\prime}\right)$ & $\begin{array}{l}\mathrm{Tm} \\
\left({ }^{\circ} \mathrm{C}\right)\end{array}$ & $\begin{array}{l}\text { Product } \\
\text { size (bp) }\end{array}$ \\
\hline \multirow{2}{*}{$\begin{array}{l}\text { Total } \\
\text { bacteria }\end{array}$} & Forward & CGGTCCAGACTCCTACGGG & \multirow[t]{2}{*}{63} & \multirow[t]{2}{*}{200} \\
\hline & Reverse & TTACCGCGGCTGCTGGCAC & & \\
\hline \multirow{2}{*}{$\begin{array}{l}\text { Escherichia } \\
\text { coli }\end{array}$} & Forward & CCGATACGCTGCCAATCAGT & \multirow[t]{2}{*}{65} & \multirow[t]{2}{*}{884} \\
\hline & Reverse & ACGCAGACCGTAGGCCAGAT & & \\
\hline \multirow{2}{*}{$\begin{array}{l}\text { K88 } \\
\text { fimbriae }\end{array}$} & Forward & GCACATGCCTGGATGACTGGT & \multirow[t]{2}{*}{63} & \multirow[t]{2}{*}{439} \\
\hline & Reverse & $\begin{array}{l}\text { CGTC } \\
\text { CGCAGAAGTAACCCCACCT }\end{array}$ & & \\
\hline \multirow{2}{*}{$\begin{array}{l}\text { Heat-stable } \\
\text { enterotoxin } \\
\text { b }\end{array}$} & Forward & TGCCTATGCATCTACACAAT & \multirow[t]{2}{*}{63} & \multirow[t]{2}{*}{110} \\
\hline & Reverse & CTCCAGCAGTACCATCTCTA & & \\
\hline \multirow{2}{*}{$\begin{array}{l}\text { Heat-stable } \\
\text { enterotoxin } \\
\text { a }\end{array}$} & Forward & ATGAAAAAGCTAATGTTGGC & \multirow[t]{2}{*}{65} & \multirow[t]{2}{*}{193} \\
\hline & Reverse & TACAACAAAGTTCACAGCAG & & \\
\hline \multirow[t]{2}{*}{$\begin{array}{l}\text { Heat-labile } \\
\text { enterotoxin }\end{array}$} & Forward & $\begin{array}{l}\text { CCGT } \\
\text { GCTGACTCTAGACCCCCA }\end{array}$ & \multirow[t]{2}{*}{68} & \multirow[t]{2}{*}{480} \\
\hline & Reverse & $\begin{array}{l}\text { CCTG } \\
\text { CTAATCTGTAACCATCCTCTGC }\end{array}$ & & \\
\hline
\end{tabular}

$\mathrm{mL}$ streptomycin. Bacterial colonies were enumerated after overnight incubation at $37^{\circ} \mathrm{C}$.

\section{RNA isolation and real-time quantitative PCR analysis}

Total RNA was isolated from jejunal and ileal mucosal samples using TRIzol reagent (Invitrogen Life Technologies, Carlsbad, CA) following the manufacturer's instruction. All RNA samples were reverse transcribed into cDNA using the Superscript FirstStrand Synthesis System (Invitrogen Life Technologies). The cDNA samples were then tested for the expression of tumor necrosis factor alpha (TNF- $\alpha$ ), interleukin $22(I L-22)$, interleukin $6(I L-6)$ and interleukin $1 \beta(I L-1 \beta)$ by real-time PCR performed as previously described [33]. Results were normalized to $\beta$ actin expression and relative quantification was calculated using the $2^{-\Delta \Delta C T}$ method. The sequences for the sense and anti-sense primers used to quantify mRNA are listed in Table 2.

\section{Bacterial DNA extraction}

Digesta samples from jejunum, ileum and colon were collected $72 \mathrm{~h}$ after infection. Total bacterial DNA was extracted using a QIAamp DNA stool mini kit (Qiagen, USA) following the manufacturer's instruction. DNA concentration and quality were checked using NanoDrop ND-2000 spectrophotometer system (Fisher Scientific, USA). Quantification of E. coli and enterotoxins (STa, STb, LT) was conducted using real-time PCR, according to a method modified from Yang et al. [34] and Wang et al [2]. Primers used for amplification of $E$. coli 
and enterotoxins in digesta samples were referenced from a previous study $[34,35]$ and listed in Table 3.

\section{Statistical analysis}

Results were expressed as means \pm SEM $\left(\mathrm{OD}_{600}\right.$, Adherence index, CFU, Diarrhea index, Gene relative expression, Fold change in luminal contents). The normality and homoscedasticity of the data herein have been tested prior to one-way ANOVA. Data that do not meet the assumptions of normality and variance homogeneity use nonparametric tests to ensure the accuracy of the analysis. Statistical differences were determined using one-way analysis of variance with Tukey's post hoc test with GraphPad Prism (GraphPad Software, San Diego, CA). Significance was defined as a $P$-value $<0.05$.

\section{Additional files}

Additional file 1: Figure S1. Authors' original data for Figure 1. (PDF $230 \mathrm{~kb}$ )

Additional file 2: Figure S2. Authors' original data for Figure 2. (PDF $422 \mathrm{~kb}$ )

Additional file 3: Figure S3. Authors' original data for Figure 3. (PDF $108 \mathrm{~kb})$

Additional file 4: Figure S4. Authors' original data for Figure 4. (PDF $429 \mathrm{~kb}$ )

Additional file 5: Figure S5. Authors' original data for Figure 5. (PDF $1207 \mathrm{~kb})$

\section{Abbreviations}

BSA: Bovine serum albumin; BW: Body weight; CFU: Colony-forming units; $E$. coli K88: Escherichia coli K88; ETEC: Enterotoxigenic Escherichia coli; FITC: Fluorescein isothiocyanate; IgG: Immunoglobulin G; IgY: Egg yolk immunoglobulins; IL-1 $\beta$ : Interleukin 1ß; IL-22: Interleukin 22; IL-6: Interleukin 6; LB: Luria-Bertani; LT: Heat-labile enterotoxin; PBS: Phosphate buffered saline; PCR: Polymerase chain reaction; STa: Heat-stable enterotoxin a; STb: Heat-stable enterotoxin b; TNF-a: Tumor necrosis factor alpha

\section{Publisher's Note}

Springer Nature remains neutral with regard to jurisdictional claims in published maps and institutional affiliations.

\section{Acknowledgements}

The authors would like to thank L. Steve for linguistic assistance in editing the manuscript.

\section{Authors' contributions}

HSY and YLL designed the study and performed the analysis; ZBW and $J L$ carried out the trial and literature review with contributions from JZL, QPW, LF and XQD; HSY, YLL, ZBW and $J$ analyzed the data and wrote the manuscript; LXW, PFH, JY and YLY collected samples, provided statistical advice and critical revision. All authors read and approved the final version of the manuscript.

\section{Funding}

This work was supported by Key Programs of Frontier Scientific Research of the Chinese Academy of Sciences (QYZDY-SSW-SMC008), National Natural Science Foundation of China (31330075), Natural Science Foundation of Hunan Province (2017JJ1020), Huxiang Youth talent Support Program (2016RS3028), Young Elite Scientists Sponsorship Program by CAST (YESS20160086). The design of this study was supported by Grant QYZDYSSW-SMC008. The sample collections were supported by Grant 31330075. The sample detection was supported by Grant 2016RS3028. The data analysis was aided by Grant 2017JJ1020. And the writing of this manuscript was supported by Grant YESS20160086.

\section{Availability of data and materials}

The data were presented in the main manuscript and available to readers.

\section{Ethics approval and consent to participate}

All animal procedures were approved by the Animal Care and Use Committee of Hunan Normal University, Changsha City, Hunan, China. The experiments were performed according to the regulations and guidelines established by this committee.

\section{Consent for publication}

Not applicable.

\section{Competing interests}

The authors declare that they have no competing interests.

\section{Author details}

${ }^{1}$ Hunan International Joint Laboratory of Animal Intestinal Ecology and Health, Laboratory of Animal Nutrition and Human Health, College of Life Sciences, Hunan Normal University, Changsha 410081, Hunan, China.

${ }^{2}$ Chinese Academy of Science, Institute of Subtropical Agriculture, Research Center for Healthy Breeding of Livestock and Poultry, Hunan Engineering and Research Center of Animal and Poultry Science and Key Laboratory for Agroecological Processes in Subtropical Region, Scientific Observation and Experimental Station of Animal Nutrition and Feed Science in South-Central, Ministry of Agriculture, Changsha City 410125, Hunan, China. ${ }^{3}$ Zyme Fast (Changsha) Biotechnology Co., Ltd, Changsha City 410311, Hunan, China.

Received: 28 June 2018 Accepted: 12 June 2019

Published online: 08 July 2019

\section{References}

1. Pultz NJ, Vesterlund S, Ouwehand AC, Donskey CJ. Adhesion of vancomycin-resistant enterococcus to human intestinal mucus. Curr Microbiol. 2006:52(3):221-4.

2. Wang W, Zijlstra RT, Gänzle MG. Identification and quantification of virulence factors of enterotoxigenic Escherichia coli by high-resolution melting curve quantitative PCR. BMC Microbiol. 2017;17(1):114-25.

3. Li X, Wang L, Zhen Y, Li S, Xu Y. Chicken egg yolk antibodies (IgY) as nonantibiotic production enhancers for use in swine production: a review. J Anim Sci Biotechnol. 2016;6:40-50.

4. Waters J, Sellwood R. Aspects of genetic resistance to K88 E. coli in pigs. In: Proceedings of the 2 nd World Congress on Genetics Applied to Livestock Production, vol. 4. Madrid: International committee for world congress on genetics applied to livestock production; 1982. p. 8.

5. Diraviyam T, Zhao B, Wang Y, Schade R, Michael A, Zhang X. Effect of chicken egg yolk antibodies (IgY) against diarrhea in domesticated animals: a systematic review and meta-analysis. PLoS One. 2014:9:e97716.

6. Cromwell GL. Why and how antibiotics are used in swine production. Anim Biotechnol. 2002:13:7-27.

7. Xu Y, Li X, Jin L, Zhen Y, Lu Y, Li S, et al. Application of chicken egg yolk immunoglobulins in the control of terrestrial and aquatic animal diseases: a review. Biotechnol Adv. 2002;29:860-8.

8. Castanon JIR. History of the use of antibiotic as growth promoters in European poultry feeds. Poult Sci. 2007;86:2466-71.

9. Dávalos-Pantoja L, Ortega-Vinuesa JL, Bastos-González D, Hidalgo-Alvarez R. A comparative study between the adsorption of lgY and lgG on latex particles. J Biomater Sci Polym Ed. 2000;11:657-73.

10. Gadde U, Rathinam T, Lillehoj HS. Passive immunization with hyperimmune egg-yolk $\lg Y$ as prophylaxis and therapy for poultry diseases - a review. Anim Health Res Rev. 2015;16:163-76.

11. Yokoyama H, Peralta RC, Diaz R, Sendo S, Ikemori Y, Kodama Y. Passive protective effect of chicken egg yolk immunoglobulins against experimental enterotoxigenic Escherichia coli infection in neonatal piglets. Infect Immun. 1992;60:998-1007.

12. Chernysheva LV, Friendship RM, Dewey CE, Gyles CL. The effect of dietary chicken egg-yolk antibodies on the clinical response in weaned pigs challenged with a K88+ Escherichia coli isolate. J Swine Health Prod. 2004;12:119-22. 
13. Jin $L Z$, Zhao $X$. Intestinal receptors for adhesive fimbriae of enterotoxigenic Escherichia coli (ETEC) K88 in swine--a review. Appl Microbiol Biotechnol. 2000;54:311-8.

14. Lee EN, Sunwoo HH, Menninen K, Sim JS. In vitro studies of chicken egg yolk antibody (IgY) against Salmonella enteritidis and Salmonella typhimurium. Poult Sci. 2002;81:632-41.

15. Shi H, Zhu J, Zou B, Shi L, Du L, Long Y, et al. Effects of specific egg yolk immunoglobulin on pan-drug-resistant Acinetobacter baumannii. Biomed Pharmacother. 2017;95:1734-42.

16. Zhen YH, Jin L, Guo J, Li XY, Lu YN, Chen J, et al. Characterization of specific egg yolk immunoglobulin (lgY) against mastitis-causing Escherichia coli. Vet Microbiol. 2008;130:126-33.

17. Imberechts H, Deprez P, Van DE, Pohl P. Chicken egg yolk antibodies against F18ab fimbriae of Escherichia coli inhibit shedding of F18 positive $E$. coli by experimentally infected pigs. Vet Microbiol. 1997;54:329-41.

18. Jin LZ, Baidoo SK, Marquardt RR, Frohlich AA. In vitro inhibition of adhesion of enterotoxigenic Escherichia coli K88 to piglet intestinal mucus by egg-yolk antibodies. FEMS Immunol Med Microbiol. 1998; 21:313-21.

19. Sunwoo HH, Lee EN, Menninen K, Suresh MR, Sim JS. Growth inhibitory effect of chicken egg yolk antibody (lgY) on Escherichia coli O157: H7. J Food Sci. 2010;67:1486-94.

20. Thu HM, Myat TW, Win MM, Thant KZ, Rahman S, Umeda K, et al. Chicken egg yolk antibodies (lgY) for prophylaxis and treatment of rotavirus diarrhea in human and animal neonates: a concise review. Korean J Food Sci Anim Resour. 2017;37:1-9.

21. Rahman S, Nguyen SV, Jr FCl, Umeda K, Kodama Y. Oral passive IgYbased immunotherapeutics: a novel solution for prevention and treatment of alimentary tract diseases. Hum Vaccin Immunother. 2013; 9:1039.

22. Arimitsu H, Sasaki K, Kohda T, Shimizu T, Tsuji T. Evaluation of Shiga toxin 2e-specific chicken egg yolk immunoglobulin: production and neutralization activity. Microbiol Immunol. 2014;58:643-8.

23. Li XY, Jin LJ, Uzonna JE, Li SY, Liu JJ, Li HQ, et al. Chitosan-alginate microcapsules for oral delivery of egg yolk immunoglobulin (IgY): In vivo evaluation in a pig model of enteric colibacillosis. Vet Immunol Immunopathol. 2009;129:132-6.

24. Zhang L, Xu YQ, Liu HY, Lai T, Ma JL, Wang JF, et al. Evaluation of Lactobacillus rhamnosus GG using an Escherichia coli K88 model of piglet diarrhoea: effects on diarrhoea incidence, faecal microflora and immune responses. Vet Microbiol. 2010;141:142-8.

25. Valeri M, Raffatellu M. Cytokines IL-17 and IL-22 in the host response to infection. Pathog Dis. 2016;74:ftw111.

26. Zhang W, Berberov EM, Freeling J, He D, Moxley RA, Francis DH. Significance of heat-stable and heat-labile enterotoxins in porcine colibacillosis in an additive model for pathogenicity studies. Infect Immun. 2006;74:3107-14.

27. Hodges K, Gil R. Infectious diarrhea: cellular and molecular mechanisms. Gut Microbes. 2010;1:4-21.

28. Bellingeri RV, Busso L, Alustiza FE, Picco NY, Molinero DP, Grosso MC, et al. Characterization of egg yolk immunoglobulin (lgY) against enterotoxigenic Escherichia coli and evaluation of its effects on bovine intestinal cells. Afr J Microbiol Res. 2013;7:398-405.

29. Gusils C, Morata V, González S. Determination of bacterial adhesion to intestinal mucus. Methods Mol Biol. 2004;268:411-5.

30. Xu FX, Xu YP, Jin LJ, Liu H, Wang LH, You JS, et al. Effectiveness of egg yolk immunoglobulin (lgY) against periodontal disease-causing Fusobacterium nucleatum. J Appl Microbiol. 2012;113:983-91.

31. Marquardt RR, Jin LZ, Jung WK, Lin F, Frohlich AA, Baidoo SK. Passive protective effect of egg-yolk antibodies against enterotoxigenic Escherichia coli K88+ infection in neonatal and early-weaned piglets. FEMS Immunol Med Microbiol. 1999;23:283-8.

32. Alustiza F, Bellingeri R, Picco N, Motta C, Grosso MC, Barbero CA, et al. IgY against enterotoxigenic Escherichia coli administered by hydrogel-carbon nanotubes composites to prevent neonatal diarrhoea in experimentally challenged piglets. Vaccine. 2016;34:3291-7.

33. Yang HS, Wu F, Long LN, Li TJ, Xiong $X$, Liao $P$, et al. Effects of yeast products on the intestinal morphology, barrier function, cytokine expression, and antioxidant system of weaned piglets. J Zhejiang Univ Sci B. 2016;17:752-62.
34. Yan Y, Galle S, Le MHA, Zijlstra RT, Gänzle MG. Feed fermentation with Reuteran- and Levan-producing Lactobacillus reuteri reduces colonization of weanling pigs by Enterotoxigenic Escherichia coli. Appl Environ Microbiol. 2015;81:5743-52.

35. Chen XY, Woodward A, Zijlstra RT, Gänzle MG. Exopolysaccharides synthesized by Lactobacillus reuteri protect against Enterotoxigenic Escherichia coli in piglets. Appl Environ Microbiol. 2014;80:5752-60.

\section{Ready to submit your research? Choose BMC and benefit from:}

- fast, convenient online submission

- thorough peer review by experienced researchers in your field

- rapid publication on acceptance

- support for research data, including large and complex data types

- gold Open Access which fosters wider collaboration and increased citations

- maximum visibility for your research: over $100 \mathrm{M}$ website views per year

At BMC, research is always in progress.

Learn more biomedcentral.com/submissions 